\title{
Oral Hygiene Behaviour Change During the Nonsurgical Periodontal Treatment Phase
}

\author{
Saeed Shamani ${ }^{1}$ and Leif Jansson ${ }^{2, *}$ \\ ${ }^{I}$ Department of Periodontology, Public Dental Service at Kaniken, Uppsala County Council, Sweden \\ ${ }^{2}$ Departments of Periodontology, Public Dental Service at Kista and Skanstull, Stockholm County Council, Sweden
}

\begin{abstract}
The purpose of the present study was to investigate the frequency of smoking cessation and the use of proximal tooth cleaning routines after a nonsurgical periodontal treatment phase in a Specialist clinic of Periodontology and to evaluate if these behaviour changes had any influence on the periodontal healing results. The investigation was conducted as a retrospective longitudinal study on a randomly selected population of 100 patients referred for periodontal treatment. The variables were registered from the dental records and the radiographs. Forty-six individuals declared that they were smokers at baseline and one individual of those quitted smoking during the nonsurgical treatment period. The percentage of individuals who performed proximal tooth cleaning daily was significantly increased from $56 \%$ to $72 \%$ during the treatment period. The patients practising proximal tooth cleaning daily had significantly lower Plaque index before as well as after the nonsurgical periodontal treatment phase compared to those without the routine. The subjects who did not perform tooth cleaning daily before the treatment and who did not introduce this routine had significantly deeper periodontal pockets compared to those who performed inter-dental cleaning daily before treatment or who had adopted the routine during the treatment phase. However, there were no significant differences according to number of deepened periodontal pockets after nonsurgical treatment irrespective of proximal cleaning routines. In the future, motivational interviewing may be a more effective method to achieve a behaviour change if an extended education of dental hygienists within this area will be implemented.
\end{abstract}

Keywords: Non-surgical treatment, oral hygiene behaviour, periodontal pocket depths, periodontitis, proximal tooth cleaning, retrospective study

\section{INTRODUCTION}

The initial phase in the traditional treatment of periodontitis consists of nonsurgical therapy including motivation, oral hygiene instructions and subgingival scaling [1]. The nonsurgical treatment period is followed by a re-evaluation at least three months after completion of the scaling [1]. The re-evaluation comprises records of plaque index, bleeding on probing and periodontal probing depth [2]. Earlier studies report reduced plaque and gingival bleeding scores from 50 $90 \%$ before treatment to $10-30 \%$ at the re-evaluation [2-4]. Subgingival instrumentation of deepened periodontal pockets followed by supportive treatment improved the periodontal conditions up to 9 months after initiation of the nonsurgical treatment [5].

The mechanical supragingival plaque control is an essential part to establish and maintain healthy periodontal conditions [6,7]. Consequently, motivational communication with the patient and oral hygiene instructions are integral tools to obtain satisfactory healing results and a good long-term prognosis. An individually designed model to motivate the patients to change the behaviour and adopt an effective su

*Address correspondence to this author at the Department of periodontology, Folktandvården, Götgatan 100, SE-118 62 Stockholm, Sweden; Tel +46 8 12316400; Fax +46 8 6446271; E-mail: leif.jansson@ftv.sll.se pragingival plaque removal is more prosperous than a standardized oral health educational programme [8].

Several longitudinal studies have evaluated the influence of smoking on periodontitis progression [9-13]. These studies have demonstrated a significant relationship between smoking and periodontitis progression, indicating that smoking is most likely a risk factor of periodontal disease [14]. In addition, the healing results after nonsurgical periodontal treatment are improved for non-smokers compared to smokers [15]. Consequently, the motivational communication during the nonsurgical periodontal treatment phase with patients using tobacco may include smoking cessation advice even if meta-analyses did not find motivational interviewing successful for smoking cessation [for review, see 16].

The purpose of the present study was to investigate the frequency of smoking cessation and the use of proximal tooth cleaning routines after a nonsurgical periodontal treatment phase in a Specialist clinic of Periodontology and to evaluate if these behaviour changes had any influence on the periodontal healing results.

\section{MATERIAL AND METHODS}

The investigation was conducted as a retrospective longitudinal study on a randomly selected population of $100 \mathrm{pa}-$ tients referred for periodontal treatment at the Public Dental 
Table 1. Means (S.D.) and Ranges for Investigated Variables

\begin{tabular}{|c|c|c|c|c|}
\hline \multirow[b]{2}{*}{ Variable } & \multicolumn{2}{|c|}{ Baseline } & \multicolumn{2}{|c|}{ Re-evaluation } \\
\hline & Mean (S.D.) & Range & Mean (S.D.) & Range \\
\hline Age & $57(10)$ & $(32-79)$ & - & - \\
\hline Smokers (\%) & 47 & - & 46 & - \\
\hline Number of teeth & $23.1(4.52)$ & $(8-30)$ & $22.5^{*}(5.07)$ & $(6-30)$ \\
\hline Number of sites with periodontal pocket depths $5-6 \mathrm{~mm}$ & $13(8.6)$ & $(0-42)$ & $6.5 *(6.1)$ & $(0-28)$ \\
\hline Number of sites with periodontal pocket depths $7-8 \mathrm{~mm}$ & $4.7(5.4)$ & $(0-24)$ & $1.8 *(3.6)$ & $(0-15)$ \\
\hline Number of sites with periodontal pocket depths $>8 \mathrm{~mm}$ & $2.8(7.8)$ & $(0-65)$ & $0.83 *(2.9)$ & $(0-25)$ \\
\hline Plaque Index & $46(24)$ & $(2-100)$ & $18 *(16)$ & $(0-59)$ \\
\hline Bleeding probing index & $21(15)$ & $(0-84)$ & $7.8 *(10)$ & $(0-75)$ \\
\hline Interdental daily cleaning (\%) & 56 & - & $72 *$ & - \\
\hline
\end{tabular}

* significant difference $(\mathrm{p}<0.01)$ between baseline and re-evaluation.

Service at Kaniken, Uppsala County Council, who fulfilled the following inclusion criteria:

- The patients had been diagnosed as having a general aggressive or chronic periodontitis.

- Nonsurgical periodontal treatment had been performed during the time period September 2008March 2010.

- The patients had not previously been treated at the specialist clinic.

- The clinical examination at baseline and at the reevaluation after the nonsurgical treatment phase had been performed by the same periodontist.

- Surgical periodontal treatment had not been performed between baseline and the re-evaluation.

A periodontist performed the clinical and radiographic examination and created an individual treatment plan for the nonsurgical treatment phase consisting of motivation, oral hygiene instructions, tooth extractions, subgingival scaling, and correction of overhangs and polishing. The periodontists as well as the dental hygienists informed the patients about the deleterious effects of smoking on periodontal health. The patients were asked about habits of proximal cleaning and in those cases when the subjects did not perform daily mechanical proximal tooth cleaning, the patients were motivated to change oral hygiene habits and instructed in the technique. From the dental records and the radiographs, the following variables were recorded:

- Age and gender at baseline.

- The number of remaining teeth at baseline, including third molars, at baseline and the re-evaluation.

- Smoking habits at baseline and the re-evaluation.

- The frequency of proximal tooth cleaning at baseline and the re-evaluation.

- The number of sites with periodontal pocket depths 5$6 \mathrm{~mm}, 7-8 \mathrm{~mm}$ and $>8 \mathrm{~mm}$ at baseline and the reevaluation. The measurements were performed to the nearest $\mathrm{mm}$ at mesial, buccal, distal and lingual aspects of each tooth.
- Bleeding on probing index at baseline and the reevaluation.

- Plaque index at baseline and the re-evaluation [17]. The variable was defined as a dichotomous variable and a plaque score of 1,2 or 3 was registered as 1 , while no presence of plaque was registered as 0 .

\section{STATISTICAL ANALYSIS}

The statistical analyses were performed by using the statistical package SPSS 18.0. Wilcoxon sign rank test was used to examine the differences for variables between baseline and the re-evaluation. The Kruskal-Wallis test was adopted to test the differences between groups depending on the daily proximal cleaning routines. Linear multiple regression analyses were used to calculate the influence of predictors on the number of deepened periodontal pockets and number of bleeding sites. Pearson's correlation coefficients were used to calculate the associations between proximal tooth cleaning daily and Plaque index. Results were considered statistically significant at $\mathrm{p}<0.05$.

\section{RESULTS}

A great majority of the subjects received the diagnosis general chronic periodontitis $(96 \%)$ and the mean age of the sample was 57 (range 32-79). The mean nonsurgical treatment period was 9.8 months (range 3-20). The baseline examinations and the re-evaluations were performed by five periodontists and the nonsurgical treatments were handled by three dental hygienists. Forty-six individuals declared that they were smokers at baseline and one individual of those quitted smoking during the nonsurgical treatment period. Thirteen percent were former smokers. Ten percent of the subjects declared that they had diabetes type II. The mean number of remaining teeth at baseline was 23.1 (Table I) and the mean number of teeth extracted during the nonsurgical treatment was 0.6 (range $0-11$ ).

The distributions according to sites with periodontal pocket depths $5-6 \mathrm{~mm}, 7-8 \mathrm{~mm}$ and $>8 \mathrm{~mm}$ are presented in Fig. (1). The mean number of sites with deepened periodontal pockets was significantly reduced after the nonsurgical treatment within all groups stratified according to pocket 
$5-6 \mathrm{~mm}$
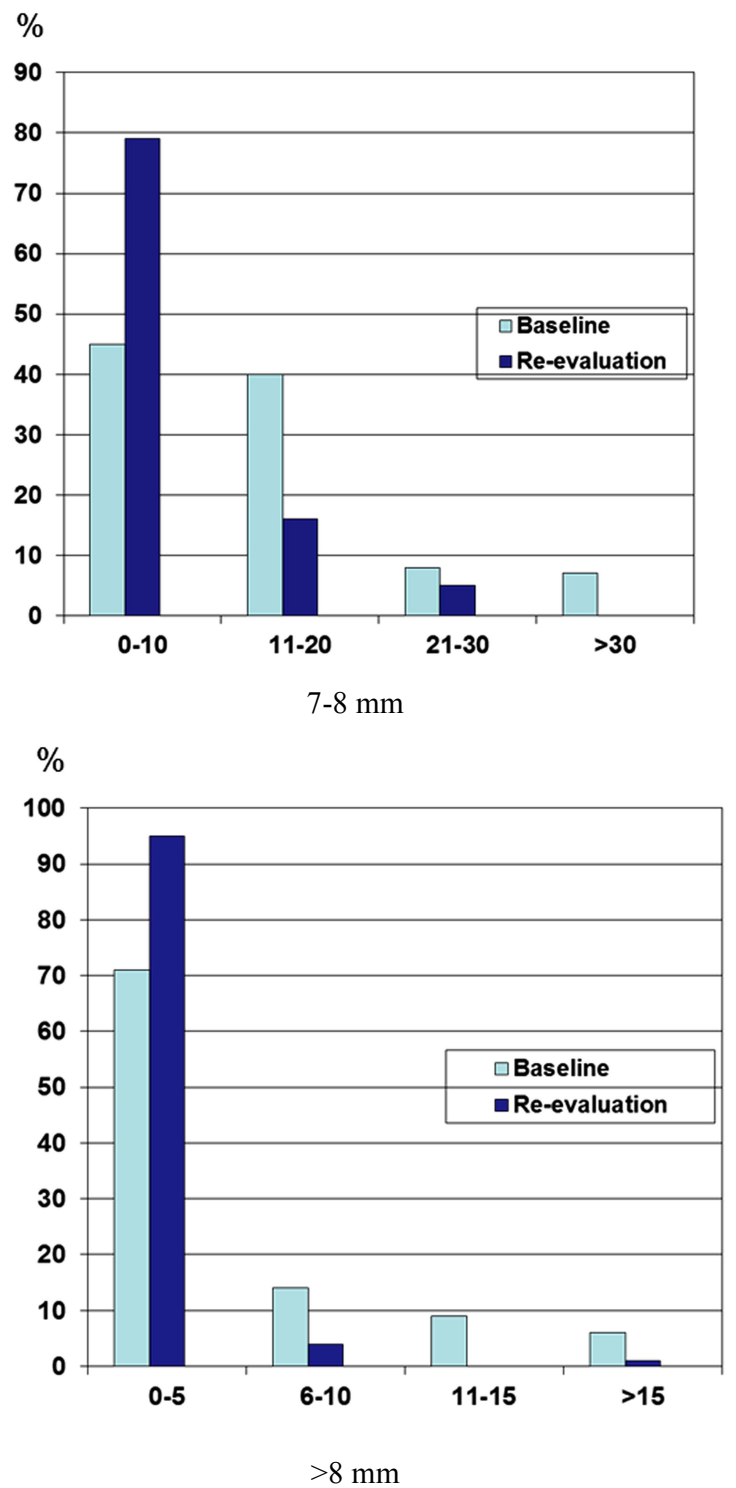

$\%$

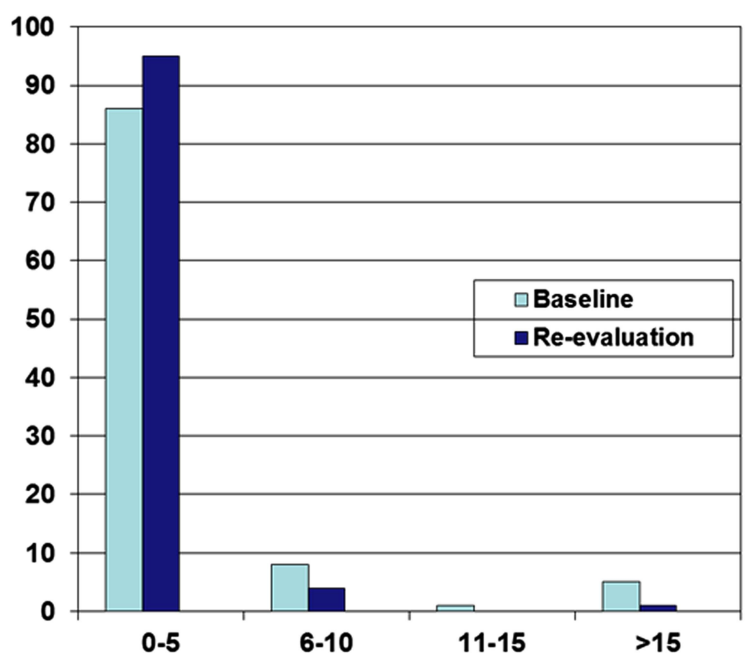

Fig. (1). The distribution of periodontal pocket depths at baseline and re-evaluation. 


\section{$\%$}

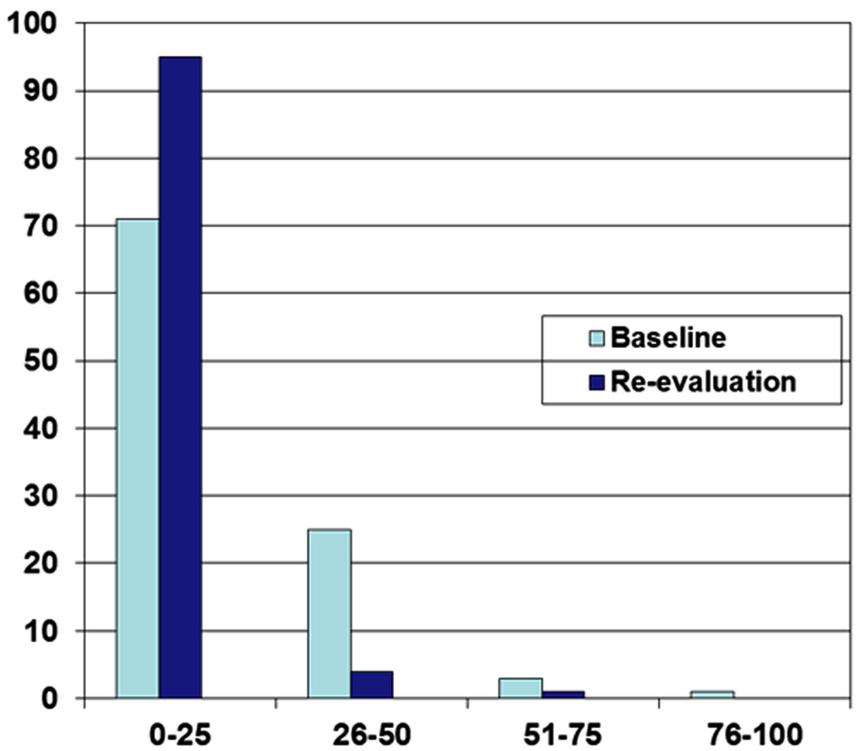

Fig. (2). The distribution of bleeding probing index at baseline and re-evaluation.

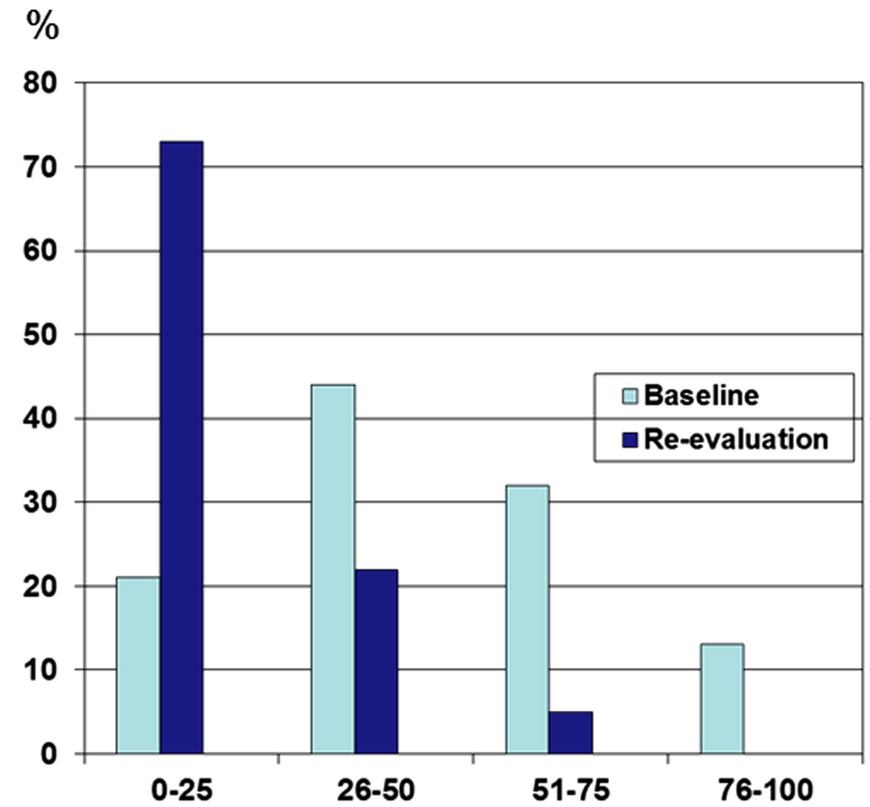

Fig. (3). The distribution of plaque index at baseline and at re-evaluation.

depths at baseline (Table I). Between baseline and the reevaluation, the percentage of individuals with a Bleeding Index $0-25 \%$ increased from $71 \%$ to $95 \%$ (Fig. 2). The mean bleeding probing index was $21 \%$ before treatment and $7.8 \%$ after treatment and this difference was significant $(\mathrm{p}<0.01)$. The percentage of subjects with Plaque Index $>50$ $\%$ was reduced from $46 \%$ at baseline to $5 \%$ at the reevaluation (Fig. 3). The mean Plaque index significantly decreased from $46 \%$ at baseline to $18 \%$ at the re-evaluation.

The percentage of individuals who performed proximal tooth cleaning daily was significantly increased from $56 \%$ to $72 \%$ during the period of nonsurgical periodontal treatment (Table 1). Fifty per cent of the patients who did not perform proximal tooth cleaning daily at baseline adopted this routine during the nonsurgical treatment phase. The subjects who did not perform proximal tooth cleaning daily before the treatment and who did not introduce this routine between baseline and the re-evaluation had significantly more sites with periodontal pocket depths 5-6 $\mathrm{mm}$ and 7-8 $\mathrm{mm}$ at baseline compared to those who performed proximal tooth cleaning daily before treatment or who had adopted the routine during the periodontal treatment phase (Table 2). In addition, the Plaque Index before as well as after the periodontal treatment was significantly higher for that group (Table 2). However, there were no significant differences according to number of deepened periodontal pockets after 
Table 2. Means (S.D.) for Investigated Variables for Groups Stratified According to a Daily Proximal Cleaning Routine

\begin{tabular}{|c|c|c|c|c|}
\hline Variable & $\begin{array}{l}\text { No Daily Proximal Cleaning } \\
\text { Routine before and after } \\
\text { Treatment }(28 \%)\end{array}$ & $\begin{array}{c}\text { Started Daily Proximal } \\
\text { Cleaning Routine after } \\
\text { Treatment }(16 \%)\end{array}$ & $\begin{array}{l}\text { Daily Proximal Cleaning } \\
\text { Routine before and after } \\
\text { Treatment }(56 \%)\end{array}$ & $\mathbf{p}$ \\
\hline Age & $52(11)$ & $59(8.9)$ & $58(9.3)$ & NS \\
\hline Smokers $(\%)$ at baseline & 47 & 38 & 56 & NS \\
\hline Number of teeth at baseline & $23.5(4.55)$ & $24.0(5.26)$ & $23.2(4.28)$ & NS \\
\hline $\begin{array}{l}\text { Number of sites with periodontal pocket depths } \\
5-6 \mathrm{~mm} \text { at baseline }\end{array}$ & $20(11)$ & $10(5.2)$ & $10(6.4)$ & $<0.01$ \\
\hline $\begin{array}{l}\text { Number of sites with periodontal pocket depths } \\
5-6 \mathrm{~mm} \text { at re-evaluation }\end{array}$ & $7.3(5.3)$ & $5.8(5.1)$ & $5.4(5.2)$ & NS \\
\hline $\begin{array}{l}\text { Number of sites with periodontal pocket depths } \\
\qquad 7-8 \mathrm{~mm} \text { at baseline }\end{array}$ & $7.1(6.3)$ & $4.2(4.7)$ & $3.1(5.0)$ & $<0.05$ \\
\hline $\begin{array}{l}\text { Number of sites with periodontal pocket depths } \\
\qquad 7-8 \mathrm{~mm} \text { at re-evaluation }\end{array}$ & $1.7(2.2)$ & $1.5(3.6)$ & $1.1(2.4)$ & NS \\
\hline $\begin{array}{l}\text { Number of sites with periodontal pocket depths } \\
\qquad>8 \mathrm{~mm} \text { at baseline }\end{array}$ & $3.5(7.0)$ & $4.8(15)$ & $1.3(3.3)$ & NS \\
\hline $\begin{array}{l}\text { Number of sites with periodontal pocket depths } \\
\qquad>8 \mathrm{~mm} \text { at re-evaluation }\end{array}$ & $0.20(0.41)$ & $1.6(5.9)$ & $0.53(1.5)$ & NS \\
\hline Plaque Index at baseline & $66(24)$ & $53(27)$ & $40(19)$ & $<0.01$ \\
\hline Plaque Index at re-evaluation & $33(16)$ & $16(9.9)$ & $12(13)$ & $<0.01$ \\
\hline Bleeding probing index at baseline & $31(14)$ & $21(20)$ & $16(10)$ & NS \\
\hline Bleeding probing index at re-evaluation & $8.3(6.2)$ & $8.2(17)$ & $7.4(7.1)$ & NS \\
\hline
\end{tabular}

Table 3. The results of Stepwise Multiple Regression Analyses with Number of Sites with Periodontal Pocket Depths 5-6 mm, 7-8 mm and $>8 \mathrm{~mm}$ and Number of Sites with Bleeding at Probing at the re-evaluation as Dependent Variables. Independent Variables were Included in the Model if $\mathbf{p}<\mathbf{0 . 0 5}$

\begin{tabular}{|c|c|c|c|c|}
\hline Dependent Variable & Independent Variables & Coefficient (B) & S.D. & $\mathbf{p}$ \\
\hline \multirow[t]{2}{*}{$\begin{array}{l}\text { Number of sites with periodontal pocket } \\
\text { depths } 5-6 \mathrm{~mm} \text { at re-evaluation }\end{array}$} & $\begin{array}{l}\text { Number of sites with periodontal pocket depth 5-6 } \\
\mathrm{mm} \text { at baseline }\end{array}$ & 0.40 & 0.06 & $<0.001$ \\
\hline & Smoking & 2.5 & 0.99 & 0.01 \\
\hline \multirow[t]{2}{*}{$\begin{array}{l}\text { Number of sites with periodontal pocket } \\
\text { depths } 7-8 \mathrm{~mm} \text { at re-evaluation }\end{array}$} & $\begin{array}{l}\text { Number of sites with periodontal pocket depths } 7-8 \\
\mathrm{~mm} \text { at baseline }\end{array}$ & 0.46 & 0.10 & $<0.001$ \\
\hline & Smoking & 3.9 & 1.1 & 0.001 \\
\hline $\begin{array}{l}\text { Number of sites with periodontal pocket } \\
\text { depths }>8 \mathrm{~mm} \text { at re-evaluation }\end{array}$ & $\begin{array}{c}\text { Number of sites with periodontal pocket depths }>8 \\
\mathrm{~mm} \text { at baseline }\end{array}$ & 0.32 & 0.02 & $<0.001$ \\
\hline $\begin{array}{c}\text { Number of sites with bleeding at probing } \\
\text { at re-evaluation }\end{array}$ & Number of sites with bleeding at probing at baseline & 0.42 & 0.05 & $<0.001$ \\
\hline
\end{tabular}

Table 4. Correlation Matrix Between the Variables Proximal Tooth Cleaning Daily and Plaque Index

\begin{tabular}{|c|c|c|c|c|c|}
\hline Proximal Tooth Cleaning Daily at Baseline & Proximal Tooth Cleaning Daily at re-evaluation & \multicolumn{2}{|c|}{$\begin{array}{c}\text { Plaque Index at } \\
\text { Baseline }\end{array}$} & \multicolumn{2}{|c|}{$\begin{array}{c}\text { Plaque Index at re- } \\
\text { evaluation }\end{array}$} \\
\cline { 3 - 6 } & & $\mathbf{r}$ & $\mathbf{p}$ & $\mathbf{r}$ & $\mathbf{p}$ \\
\hline \hline No & Yes & -0.40 & 0.001 & -0.38 & 0.001 \\
\hline Yes & Yes & -0.52 & $<0.001$ & -0.57 & $<0.001$ \\
\hline
\end{tabular}

nonsurgical treatment irrespective of proximal cleaning routines (Table 2).

The number of sites with periodontal pocket depths 5-6 $\mathrm{mm}$ and $7-8 \mathrm{~mm}$ at the re-evaluation were significantly increased for smokers compared to non-smokers when the number of sites with deepened pockets at baseline was included as independent variable in the multiple regression analyses (Table 3). None of the other investigated variables was significantly correlated to the number of deepened periodontal pockets at the re-evaluation.

The patients practising proximal tooth cleaning daily had significantly lower Plaque index before as well as after the nonsurgical periodontal treatment phase compared to those without the routine (Table 4). Individuals who adopted 
proximal tooth cleaning during the nonsurgical treatment period had a significantly lower plaque index even at baseline compared to those who did not change oral hygiene routines (Table 4).

\section{DISCUSSION}

This is a retrospective study consisting of subjects referred to a specialist clinic and a great majority of the patients of the present study had the diagnosis general chronic periodontitis. Thus, the material may be regarded as representative for a periodontitis prone population in Sweden.

The smoking habits and the frequency of proximal tooth cleaning were self-reported data. The validity of selfreported smoking habits has been studied in a review study with meta-analysis [18]. The sensitivity was reported to vary between $6 \%$ and $100 \%$ and the specificity ranged from $33 \%$ to $100 \%$. Interviewer-administered questionnaires and adult individuals increased the sensitivity and the specificity. The conclusion of the study was that self-reported data of smoking habits were found to be accurate in most studies.

The periodontal pocket depths were significantly reduced after the non-surgical periodontal treatment phase. This result is in accordance with several earlier studies [19-24]. The pocket depth reduction depends on the clinical attachment gain as well as the recession of the marginal level. In the present study, no distinction has been made between sites on molars and one-rooted teeth, while many studies report the pocket depth changes on non-molar sites only. In addition, the initial periodontal pocket depth is correlated to the magnitude of the pocket depth reduction and this result is in accordance with earlier studies [24].

The healing results after nonsurgical therapy is less favourable in smokers compared to non-smokers [for review, see 25]. These results are in accordance with the results in this study. Since the frequency of smokers vary in different studies studying the healing results after periodontal therapy, the variation according to the degree of pocket depth reduction may explain some of the variability. The cessation of smoking has been found to reduce the periodontitis progression in earlier reports $[10,12,13]$. Consequently, the cessation of smoking should be regarded as an essential part of the periodontal therapy plan. An earlier American study reported that most individuals who quitted smoking used individual methods and did not use an organized cessation program [26]. Several smoking cessation programs have been used, such as brief advice, brief advice and reminder, nicotine gums, minimal or extended intervention [27]. In studies from USA and UK, quit rates between 2.4 and $44.4 \%$ were reported [27]. In the present study, all patients have been informed about the harmful effects of smoking on the progression on the periodontal disease. However, the quit rate was $1 \%$ only, and this can probably be explained by weak effects of brief advices and a follow-up period between 3 and 20 months. It is likely that a longer follow-up time than 3-20 months could have increased the quit rate. The education of dental hygienists and dentists in successful smoking cessation methods may be an integral part of their further training. If effective cessation programmes are implemented in the dental clinics, quit rates between 10 and $15 \%$ can be expected [27].
For periodontitis patients, the use of inter-dental brushes is regarded as the ideal tool for proximal cleaning. The percentage of individuals who performed proximal tooth cleaning daily was significantly increased from $56 \%$ to $72 \%$ during the period of nonsurgical periodontal treatment. In a Swedish national dental survey [28], $46 \%$ of adults used tooth picks and $12 \%$ used dental floss on a daily basis. Selfreported data in a retrospective study on dentate individuals showed that $50-65 \%$ regularly used some kind of inter-dental cleaning. In an earlier study at the same clinic as the present investigation, the two participating groups of patients reported daily inter-dental cleaning in $38 \%$ and $46 \%$ of the cases [8]. In a random-sample of 35-year-old citizens in Oslo, 28\% declared that they performed regular inter-dental cleaning [29]. In a Finnish study on 55-year-old subjects [30], individuals with a healthy lifestyle and females used extra cleaning methods (tooth picks, dental floss, inter-dental brush) more often. Consequently, inter-dental cleaning is not widespread in Scandinavian populations and varies depending on background factors.

The effectiveness of oral hygiene instructions is often poor $[31,32]$. Recently, the technique of motivational interviewing has been practised in order to change patient behaviour [for review, see 16] and is suitable to be a part of the individual treatment plan. The effectiveness of an individually tailored oral health programme in subjects with periodontal disease has been evaluated in a Swedish study [8]. The Gingival Index score as well as the Plaque Index score were significantly lower at follow-up for individuals receiving an individually tailored oral health programme (experimental group) compared to those patients allocated to a standard treatment programme (control group). The Plaque Index was reduced from $74 \%$ at baseline to $14 \%$ at 12 -month follow-up in the experimental group. In the control group, the corresponding frequencies were $73 \%$ and $32 \%$, respectively. In the present study, the Plaque Index at the follow-up was $18 \%$. However, in the experimental study [8] a Plaque Index of at least $30 \%$ at baseline was required in the inclusion criteria. The frequency of inter-dental cleaning did not have any significant influence on the magnitude of the reduction of the periodontal pocket depths at follow-up and this result is in accordance with the results in the experimental study [33], where no significant difference according to pocket depth reduction was found between the group receiving an individually tailored oral health programme and the control group. These results indicate a significant effect of the nonsurgical treatment in a short-term perspective irrespective of the inter-dental cleaning habits.

\section{CONCLUSION}

It is generally accepted that smoking and plaque are welldocumented risk factors of periodontitis. Thus, smoking cessation and appropriate tooth cleaning appear to belong to the most important factors in order to manage chronic periodontitis [34]. However, brief advices about the effects of smoking cessation and the use of daily interdental cleaning has not found to be an effective tool to change individual habits. In the future, motivational interviewing may be a more effective method to achieve a behaviour change if an extended education of dental hygienists within this area will be implemented. 


\section{CONFLICT OF INTEREST}

The authors declare that they have no competing interests.

\section{ACKNOWLEDGEMENT}

Declared none.

\section{REFERENCES}

[1] Claffey N, Polyzois I, Ziaka P. An overview of nonsurgical and surgical therapy. Periodontology 2000 2004; 36: 35-44.

[2] Claffey N, Polyzois, In: Lindhe J, Lang NP, Karring T, Eds. Clinical Periodontology and Implant Dentistry. Oxford: Blackwell Munksgaard 2008; pp. 766-82.

[3] Axelsson P, Lindhe J. Effect of controlled oral hygiene procedures on caries and periodontal disease in adults. J Clin Periodontol 1978; 5: 133-51.

[4] Axelsson P, Lindhe J. The significance of maintenance care in the treatment of periodontal disease. J Clin Periodontol 1981; 8: 28194.

[5] Badersten A, Nilvéus R, Egelberg J. Effect of non-surgical periodontal therapy. II. Severely advanced periodontitis. J Clin Periodontol 1984; 11: 63-76.

[6] Hujoel PP, Löe H, Ånerud Å, Boysen H, Leroux BG. Fort-fiveyear tooth survival probabilities among men in Oslo, Norway. J Dent Res 1998; 77: 2020-7.

[7] Axelsson P, Nyström B, Lindhe J. The long-term effect of a plaque control program on tooth mortality, caries and periodontal disease in adults. Results after 30 years of maintenance. J Clin Periodontol 2004; 31: 749-57.

[8] Jönsson B, Öhrn K, Oscarson N, Lindberg P. The effectiveness of an individually tailored oral health educational programme on oral hygiene behaviour in patients with periodontal disease: a blinded randomized-controlled clinical trial (one-year follow-up). J Clin Periodontol 2009; 36: 1025-34.

[9] Ismail AI, Morrison EC, Burt BA, Caffesse RG, Kavanagh MT. Natural history of periodontal disease in adults: findings from the tecumseh periodontal disease study 1959-87. J Dent Res 1990; 69: 430-5.

[10] Bolin A, Eklund G, Frithiof L, Lavstedt S. The effect of changed smoking habits on marginal alveolar bone loss. Swed Dent J 1993; 17: 211-6.

[11] Norderyd O, Hugoson A, Grusovin G. Risk for severe periodontal disease in a Swedish adult population. J Clin Periodontol 1999; 26: 608-15.

[12] Bergström J, Eliasson S, Dock J. A 10-year prospective study of tobacco smoking and periodontal health. J Periodontol 2000; 71: $1338-47$.

[13] Jansson L, Lavstedt S. Influence of smoking on marginal bone loss and tooth loss - a prospective study over 20 years. J Clin Periodontol 2002; 29: 750-6.

[14] Page RC, Beck JD. Risk assessment for periodontal diseases. Int Dent J 1997; 47: 61-87.

[15] Grossi SG, Zambon J, Machtei EE, et al. Effects of smoking and smoking cessation on healing after mechanical periodontal therapy. J Am Dent Assoc 1997; 128: 599-607.
[16] Ramseier CA, Catley D, Krigel S, Bagramian RA. In: Lindhe J, Lang NP, Karring T, Eds. Clinical Periodontology and Implant Dentistry. Oxford: Blackwell Munksgaard 2008; pp. 695-704.

[17] Silness J, Löe H. Periodontal disease in pregnancy. II. Prevalence and severity. Acta Odont Scand 1964; 22: 121-35.

[18] Patrick DL, Cheadle A, Thompson DC, Diehr P, Koepsell T, Kinne S. The validity of self-reported smoking: a review and metaanalysis. Am J Public Health 1994; 84(7): 1086-93.

[19] Morrison EC, Ramfjord SP, Hill RW. Short term effects of initial nonsurgical periodontal treatment (hygienic phase). J Clin Periodontol 1980; 7: 199-211.

[20] Badersten A, Nilvéus R, Egelberg J. Effect of non-surgical periodontal therapy. VIII. Probing attachment changes related to clinical characteristics. J Clin Periodontol 1987; 14: 425-32.

[21] Badersten A, Nilvéus R, Egelberg J. Four-year observations of basic periodontal therapy. J Clin Periodontol 1987; 14: 438-44.

[22] Proye M, Caton J, Polson A. Initial healing of periodontal pockets after a single episode of root planning monitored by controlled probing force. J Periodontol 1982; 53: 296-301.

[23] Claffey N, Loos B, Gantes B, Martin M, Heins P, Egelberg J. The relative effects of therapy and periodontal disease on loss of probing attachment after root debridement. J Clin Periodontol 1988; 15: 163-9.

[24] Adriaens P A, Adriaens L M. Effects of nonsurgical periodontal therapy on hard and soft tissues. Periodontology 2000 2004; 36: 121-45.

[25] Obeid P, Bercy P. Effects of smoking on periodontal health: a review. Adv Ther 2000; 17: 230-7.

[26] Fiore MC, Pierce JP, Giovano GA, et al. Methods used to quit smoking in the united states. do cessation programs help? J Am Med Assoc 1990; 263: 2760-5.

[27] Warnakulasuriya S. Effectiveness of tobacco counseling in the dental office. J Dent Educ 2002; 66(9): 1079-87.

[28] Håkanson J. Dental care habits, attitudes towards dental health and dental status among 20 to 60 year old individuals in Sweden. Ph.D. dissertation. Dept. of Dentistry, University of Lund 1978.

[29] Hansen BF, Bjertness E, Gjermo P. Changes in periodontal disease indicators in 35-year-old Oslo citizens from 1973 to 1984. J Clin Periodontol 1990; 17: 249-54

[30] Sakki TK, Knuuttila ML, Anttila SS. Lifestyle, gender and occupational status as determinants of dental health behavior. J Clin Periodontol 1998; 25: 566-70.

[31] Johansson LA, Oster B, Hamp SE. Evaluation of cause-related periodontal therapy and compliance with maintenance care recommendations. J Clin Periodontol 1984; 11: 689-99.

[32] Schuz B, Sniehotta FF, Wiedemann A, Seemann R. Adherence to a daily flossing regimen in university students: effects of planning when, where, how and what to do in the face of barriers. J Clin Periodontol 2006; 33: 612-9.

[33] Jönsson B, Öhrn K, Lindberg P, Oscarson N. Evaluation of an individually tailored oral health educational programme on periodontal health. J Clin Periodontol 2010; 37: 912-9.

[34] Ramseier C A. Potential impact of subject-based risk factor control on periodontits. J Clin Periodontol 2005; 32(Suppl.6): 283-90.

(c) Shamani and Jansson; Licensee Bentham Open.

This is an open access article licensed under the terms of the Creative Commons Attribution Non-Commercial License (http://creativecommons.org/licenses/by-nc/3.0/) which permits unrestricted, non-commercial use, distribution and reproduction in any medium, provided the work is properly cited. 